\title{
Suppression of PP2A is critical for protection of melanoma cells upon endoplasmic reticulum stress
}

\author{
KH Tay ${ }^{1,2}$, L Jin $^{3}$, H-Y Tseng ${ }^{1,2}$, CC Jiang ${ }^{1,2}$, Y Ye ${ }^{1,2}$, RF Thorne ${ }^{2,4}$, T Liu $^{5}$, ST Guo ${ }^{6}$, NM Verrills ${ }^{2,4}$, P Hersey ${ }^{3}$ and XD Zhang ${ }^{\star, 1,2,6}$
}

Endoplasmic reticulum (ER) stress triggers apoptosis by activating Bim in diverse types of cells, which involves dephosphorylation of Bim $\mathrm{EL}_{\mathrm{L}}$ by protein phosphatase $2 \mathrm{~A}$ (PP2A). However, melanoma cells are largely resistant to ER stressinduced apoptosis, suggesting that Bim activation is suppressed in melanoma cells undergoing ER stress. We show here that ER stress reduces PP2A activity leading to increased ERK activation and subsequent phosphorylation and proteasomal degradation of $\mathrm{Bim}_{\mathrm{EL}}$. Despite sustained upregulation of Bim at the transcriptional level, the $\mathrm{Bim}_{\mathrm{EL}}$ protein expression was downregulated after an initial increase in melanoma cells subjected to pharmacological ER stress. This was mediated by increased activity of ERK, whereas the phosphatase activity of PP2A was reduced by ER stress in melanoma cells. The increase in ERK activation was, at least in part, due to reduced dephosphorylation by PP2A, which was associated with downregulation of the PP2A catalytic $C$ subunit. Notably, instead of direct dephosphorylation of Bim $\mathrm{EL}_{\mathrm{L}}, \mathrm{PP2A}$ inhibited its phosphorylation indirectly through dephosphorylation of ERK in melanoma cells. Taken together, these results identify downregualtion of PP2A activity as an important protective mechanism of melanoma cells against ER stress-induced apoptosis.

Cell Death and Disease (2012) 3, e337; doi:10.1038/cddis.2012.79; published online 28 June 2012

Subject Category: Cancer

A number of cellular stress conditions, such as nutrient deprivation, hypoxia, alterations in glycosylation status, and disturbances of calcium flux, trigger accumulation and aggregation of unfolded and/or misfolded proteins in the endoplasmic reticulum (ER) lumen leading to so-called ER stress. ${ }^{1,2}$ The ER responds to the stress conditions by activation of a range of signaling pathways to alter transcriptional and translational programs, which couples the ER protein folding load with the ER protein folding capacity and is termed the ER stress response or the unfolded protein response (UPR). ${ }^{1,2}$ The UPR is fundamentally a cytoprotective response, but excessive or prolonged UPR resulting from irrevocable ER stress can cause apoptosis. ${ }^{1-4}$ This involves many of the same molecules that have important roles in other apoptotic cascades. ${ }^{3-5}$ Among them, the $\mathrm{BH} 3-$ only protein Bim appears of particular importance because it mediates ER stress-induced apoptosis in diverse types of cells. ${ }^{6}$

Activation of Bim in cells undergoing ER stress is regulated by both transcriptional and post-translational mechanisms. ${ }^{6}$ Transcriptional upregulation of Bim by ER stress is mediated by the transcription factor CHOP and its cofactor C/EBP $\alpha$ that form heterodimers, which activate a non-conventional promoter within the first intron of the bim gene. ${ }^{6}$ At the posttranslational level, ER stress triggers protein phosphatase $2 \mathrm{~A}$
(PP2A)-mediated dephosphorylation of Bim, in particular, the

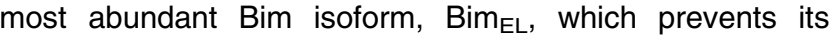
ubiquitination and proteasomal degradation, thus leading to its increase in expression. ${ }^{6}$ Bim $_{\mathrm{EL}}$ is known to subject to phosphorylation by the MEK/ERK pathway that targets it for degradation..$^{7,8}$ It can also be phosphorylated by JNK resulting in its disassociation from the dynein light chain of the microtubule and induction of apoptosis. ${ }^{7}$

PP2A represents a family of serine/threonine phosphatases that regulate numerous intracellular signaling cascades. ${ }^{9,10}$ Typically, PP2A contains a highly active core dimer composed of a catalytic $C$ subunit (PP2A-C) and a structural $A$ subunit (PP2A-A) that recruits one of multiple regulatory $B$ subunits (PP2A-B) to form the PP2A heterotrimeric complex.,10 The substrate specificity of PP2A is determined by the $B$ subunit in the complex, whereas the dynamic exchange of $B$ subunits in the complex is regulated by reversible methylation and phosphorylation of the C-terminal tail of PP2A-C.,10 Noticeably, there is increasing evidence showing that PP2A has an important tumor-suppressive role, and various PP2A subunits has also been reported to be downregulated in a number of cancers including melanoma. ${ }^{11-13}$

Most cultured human melanoma cell lines are not sensitive to apoptosis induced by pharmacological ER stress inducers, ${ }^{14,15}$ suggesting that melanoma cells have largely

\footnotetext{
${ }^{1}$ School of Medicine and Public Health, University of Newcastle, Newcastle, New South Wales 2308, Australia; ${ }^{2}$ Priority Research Center for Cancer Research, University of Newcastle, Newcastle, New South Wales 2308, Australia; ${ }^{3}$ Kolling Institute for Medical Research, University of Sydney, Sydney, New South Wales 2065, Australia; ${ }^{4}$ School of Biomedical Science, University of Newcastle, Newcastle, New South Wales 2308 , Australia; ${ }^{5}$ Children's Cancer Institute Australia, University of New South Wales, Sydney, New South Wales 2052, Australia and ${ }^{6}$ Department of Molecular Biology, Shanxi Cancer Hospital and Institute, Shanxi 030013, China ${ }^{*}$ Corresponding author: XD Zhang, School of Medicine and Public Health, University of Newcastle, David Maddison Clinical Sciences Building, Cnr. King \& Watt Streets, Newcastle, New South Wales 2300, Australia. Tel: +61 2 49138174; Fax: +61 2 49138184; E-mail: Xu.Zhang @newcastle.edu.au

Keywords: ER stress; PP2A; MEK/ERK; Bim; melanoma

Abbreviations: $E R$, endoplasmic reticulum; OA, okadaic acid; 4-OHT, 4-hydroxytestosterone; PP2A, protein phosphatase 2A; PP2A-A, PP2A structural A subunit; PP2A-B, PP2A regulatory B subunit; PP2A-C, PP2A catalytic $C$ subunit; TG, thapsigargin; TM, tunicamycin; UPR, unfolded protein response

Received 23.4.12; revised 21.5.12; accepted 24.5.12; Edited by H-U Simon
} 
adapted to ER stress conditions. In support, the UPR is constitutively activated in melanoma cells in vitro and in vivo. ${ }^{16,17}$ Although the adaptive mechanism(s) developed by melanoma cells are not fully understood, we have previously found that upregulation of the anti-apoptotic protein $\mathrm{Mcl}-1$ is critical for survival of melanoma cells upon ER stress. $^{14}$ When $\mathrm{Mcl}-1$ is inhibited, ER stress induces apoptosis by activation of the $\mathrm{BH} 3-$ only proteins Noxa and PUMA. ${ }^{14}$ In contrast, Bim does not have a role in ER stressinduced apoptosis of melanoma cells deficient in Mcl-1. ${ }^{14}$ However, the mechanism by which Bim is inhibited in melanoma cells undergoing ER stress remains undefined.

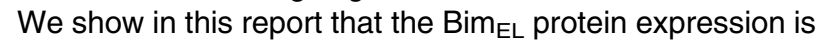
rapidly downregulated after an initial increase, despite sustained upregulation of the Bim transcript, in melanoma cells submitted to ER stress, and that the decrease in Bim $_{\mathrm{EL}}$ is due to reduction in PP2A activity leading to increased activation of ERK and subsequent phosphorylation and proteasomal degradation of the protein. In addition, we demonstrate that, instead of directly dephosphorylating Bim, PP2A reduces Bim phosphorylation indirectly by dephosphorylation of ERK in melanoma cells.

\section{Results}

ER stress does not induce sustained upregulation of Bim $_{\mathrm{EL}}$ in melanoma cells. ER stress triggers apoptosis through activation of Bim in diverse types of cells, ${ }^{6}$ but treatment with the ER stress inducer tunicamycin (TM) induced only a moderate, transient increase in the Bim $\mathrm{EL}_{\mathrm{L}}$ protein expression, which was followed by a decrease in Mel-RM cells (Figure 1a). By $36 \mathrm{~h}$ after treatment, the Bim $\mathrm{EL}_{\mathrm{L}}$ protein level was even lower than that in untreated cells (Figure 1a). The decrease in the Bim $\mathrm{EL}_{\mathrm{L}}$ expression at relatively late stages (24 and $36 \mathrm{~h}$ ) after exposure to TM was also observed in another 3 melanoma cell lines (Figure 1b). In contrast, TM triggered sustained upregulation of Bim in MCF-7 breast cancer cells (Figure 1a). ${ }^{6}$ Consistent with previous reports, ${ }^{6,14,15}$ melanoma cells were relatively resistant ( $<20 \%$ apoptotic cells at $48 \mathrm{~h}$ after treatment), whereas MCF-7 cells were sensitive to TM-induced apoptosis (Figure 1c).

Downregulation of the Bim $\mathrm{EL}_{\mathrm{L}}$ protein after its initial increase by ER stress in melanoma cells was further confirmed with another ER stress inducer thapsigargin (TG) (Figure 1d). The ER stress-induced changes in the Bim $\mathrm{EL}_{\mathrm{L}}$ expression in melanoma cells appeared specific because, as reported before ${ }^{14} \mathrm{ER}$ stress triggered sustained upregulation of the related $\mathrm{Bcl}-2$ family proteins, $\mathrm{Mcl}-1$ and PUMA, and caused no change in the expression of Bid and $\mathrm{Bcl}-\mathrm{X}_{\mathrm{L}}$ in melanoma cells (Supplementary Figure 1). Induction of ER stress by TM and TG was corroborated by upregulation of GRP78, CHOP, and the active form of the XBP1 mRNA (Figure 1e and Supplementary Figure 2).

Suppression of Bim has an important role in resistance of melanoma cells to ER stress-induced apoptosis. Having established that ER stress does not induce sustained upregulation of $\mathrm{Bim}_{\mathrm{EL}}$ in melanoma cells, we examined whether this has a role in protecting melanoma cells from ER stress-induced apoptosis. To this end, we used a lentivirusbased inducible gene expression system to establish a Mel-RM sub-line (Mel-RM.Bim) to overexpress Bim $\mathrm{EL}_{\mathrm{L}}$ conditionally in response to 4-hydroxytestosterone (4-OHT) (Figure 2a). ${ }^{18}$ Induction of $\mathrm{Bim}_{\mathrm{EL}}$ by $4-\mathrm{OHT}$ triggered apoptosis in Mel-RM.Bim cells (Figure 2b), which was markedly enhanced by cotreatment with TM (Figures 2a and b), suggesting that melanoma cells are sensitive to ER stress-induced apoptosis provided Bim is expressed at relatively high levels. The effect of overexpression of $\mathrm{Bim}_{\mathrm{EL}}$ on sensitivity of melanoma cells to TM-induced apoptosis was confirmed in another two melanoma lines transiently transfected with a construct expressing Bim $\mathrm{EL}_{\mathrm{L}}$ (Figures 2c and d).

ER stress induces transcriptional upregulation of Bim in melanoma cells. Like in other cell types, ${ }^{6}$ ER stress induced sustained upregulation of the Bim transcript in Mel-RM cells (Figure 3a). This upregulation was due to a transcriptional increase mediated by the transcription factor CHOP, ${ }^{6}$ as small interference RNA (siRNA) knockdown of CHOP markedly inhibited the increase in Bim mRNA levels, partially recapitulating the effect of the transcription inhibitor actinomycin D (Figures $3 b$ and $c$ ). Upregulation of Bim mRNA by ER stress was confirmed in another three melanoma cell lines (Supplementary Figure 3).

To examine whether disassociation between the Bim protein expression and its transcriptional upregulation is specific to melanoma cells under ER stress, we established a Mel-RM sub-line (Mel-RM.CHOP) that expressed CHOP conditionally in response to 4-OHT (Figure $3 \mathrm{~d}$ ). Induction of $\mathrm{CHOP}$ resulted in persistent increases in Bim at both the mRNA and protein levels and caused apoptosis (Figures 3d and e), suggesting that downregulation of the Bim protein after its initial upregulation despite its sustained transcriptional increase mediated by CHOP is specific to melanoma cells undergoing ER stress.

The decrease in Bim in melanoma cells undergoing ER stress is due to proteasomal degradation mediated by MEK/ERK signaling. Treatment with the proteasome inhibitor MG132 inhibited downregulation of the Bim $\mathrm{EL}_{\mathrm{L}}$ protein in Mel-RM cells exposed to TM (Figure 4a), indicating that its decrease in melanoma cells under ER stress is associated with proteasomal degradation. In support, protein half-life analysis showed that the Bim $\mathrm{EL}_{\mathrm{L}}$ turnover rate was more rapid in melanoma cells treated with TM compared with those without exposure to TM (Figure 4b), in contrast to the increased Bim $\mathrm{EL}_{\mathrm{L}}$ half-life time in MCF-7 cells undergoing ER stress (Supplementary Figure 4). ${ }^{6}$ Similarly, the Bim $\mathrm{EL}_{\mathrm{L}}$ protein underwent a retarded mobility shift (slower migration in SDS-PAGE), consistent with increased phosphorylation of $\operatorname{Bim}_{E L}, 7,8,19$ in melanoma cells during ER stress (Figures 1a, b and d), whereas it underwent an opposite pattern of mobility shift (faster migration in SDS-PAGE) (Figure 1a), consistent with its dephosphorylation, ${ }^{6}$ in MCF-7 cells. The increase in Bim $\mathrm{EL}_{\mathrm{L}}$ phosphorylation in melanoma cells undergoing ER stress was confirmed using an antibody that specifically recognizes Bim $_{\mathrm{EL}}$ phosphorylated at Ser69 (Figures $4 \mathrm{c}$ and $\mathrm{d}$ ). Consistently, although there was an 
a
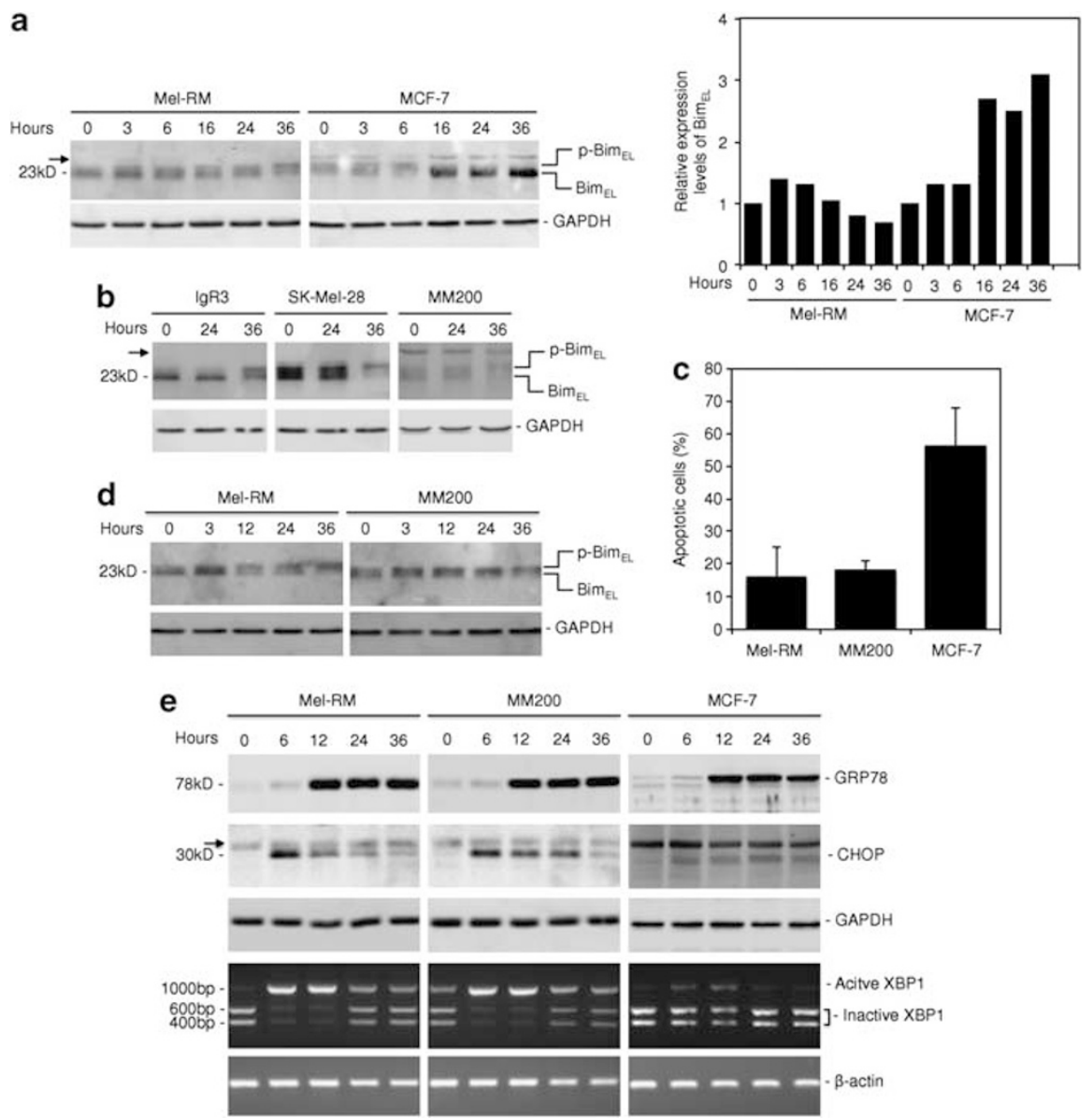

Figure 1 ER stress does not induce sustained upregulation of $\operatorname{Bim}_{E L}$ in melanoma cells. (a) TM induces sustained upregulation of Bim $\mathrm{EL}_{\mathrm{L}}$ in $\mathrm{MCF}-7$ breast cancer cells but not in Mel-RM melanoma cells. Left: $30 \mu \mathrm{g}$ of total protein of whole-cell lysates from Mel-RM and MCF-7 cells treated with TM $(3 \mu \mathrm{M})$ for indicated periods were subjected to western blot analysis of Bim and GAPDH (as a loading control). The arrowhead points to a band of unknown origin generated with the antibody against Bim. Right: quantitative expression levels of Bim $\mathrm{EL}_{\mathrm{L}}$ as shown the left panel that were normalized to GAPDH. Quantitation of each band was carried out with ImageReader LAS-4000. The data shown are representative of three individual experiments. (b) TM does not induce sustained upregulation of Bim $\mathrm{EL}_{\mathrm{L}}$ in IgR3, Sk-Mel-28, and MM200 melanoma cells. Thirty microgram of total protein of whole-cell lysates from IgR3, Sk-Mel-28, and MM200 treated with TM ( $3 \mu \mathrm{M})$ for indicated periods were subjected to western blot analysis of Bim and GAPDH (as a loading control). The arrowhead points to a band of unknown origin generated with the antibody against Bim. The data shown are representative of three individual experiments. (c) Melanoma cells are not sensitive to ER stress-induced apoptosis. Mel-RM and MM200 melanoma cells, and MCF-7 breast cancer cells were treated with TM $(3 \mu \mathrm{M})$ for $48 \mathrm{~h}$ before apoptosis was measured by the PI method using flow cytometry. The data shown are the mean \pm S.E. of three individual experiments. (d) TG does not induce sustained upregulation of Bim $_{E L}$ in melanoma cells. Thirty microgram of total protein of whole-cell lysates from Mel-RM and MM200 melanoma cells treated with TG $(1 \mu \mathrm{M})$ for indicated periods were subjected to western blot analysis of Bim and GAPDH (as a loading control). The data shown are representative of three individual experiments. (e) Induction of ER stress by TM in Mel-RM and MM200 melanoma cells and MCF-7 breast cancer cells. Mel-RM, MM200, and MCF-7 cells were treated with TM $(3 \mu \mathrm{M})$ for indicated periods. For examining the expression of GRP78 and CHOP, $30 \mu \mathrm{g}$ of total protein of whole-cell lysates were subjected to western blot analysis of GRP78, CHOP, and GAPDH (as a loading control). The arrowhead points to a non-specific band generated with the antibody against CHOP. For examining activation of XBP1, RT-PCR products of XBP1 mRNA and $\beta$-actin mRNA (as a control) from total RNA extracts were digested with ApaLl for 90 min followed by electrophoresis. The longer fragment derived from the active form of XBP1 mRNA and two shorter bands derived from the inactive form are indicated. The data shown are representative of three individual experiments

increase in ubiquitination of Bim in melanoma cells after treatment with TM, Bim ubiquitination was reduced in MCF-7 cells undergoing ER stress as reported by others (Figure 4e). ${ }^{6}$

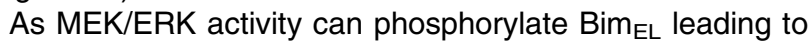
its ubiquitination and proteasomal degradation, ${ }^{7,8}$ we examined whether this is involved in Bim $\mathrm{EL}_{\mathrm{L}}$ phosphorylation in melanoma cells upon ER stress. Treatment with the MEK inhibitor U0126 upregulated $\mathrm{Bim}_{\mathrm{EL}}$ in melanoma cells exposed to TM, which was associated with reduction in its phosphorylation (Figure 4f), indicating that MEK/ERK signaling has an important role in phosphorylation of $\mathrm{Bim}_{\mathrm{EL}}$ and downregulation of its expression. Notably, phosphorylation of ERK was increased, albeit moderately, by induction of ER stress (Figure $4 \mathrm{f}$ and Supplementary Figure 5). The effect of MEK/ERK signaling on phosphorylation of Bim in melanoma cells under ER stress was further confirmed by knockdown of MEK1 (Figure 4g). Moreover, the effect was similarly observed in additional two melanoma lines treated with U0126 plus TM (Supplementary Figure 6).

ER stress reduces the phosphatase activity of PP2A in melanoma cells. The PP2A is responsible for dephosphorylation of Bim and contributes to its upregulation in many 


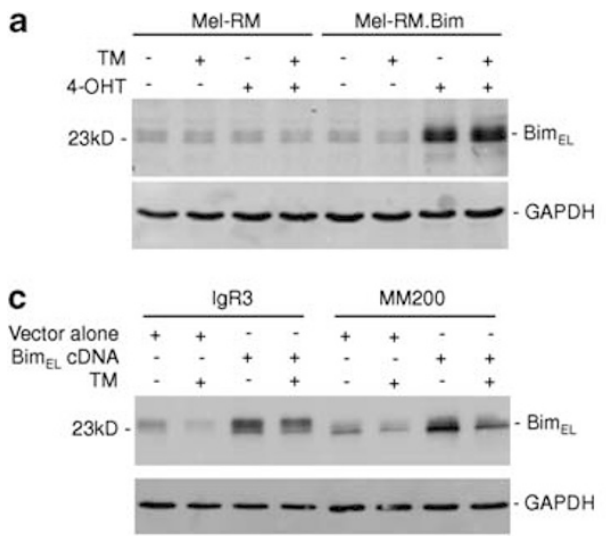

b
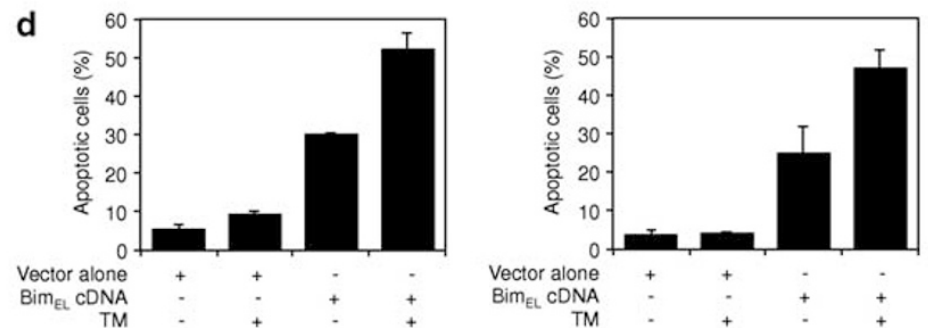

Figure 2 ER stress induces increased apoptosis when Bim $\mathrm{EL}_{\mathrm{L}}$ is expressed at high levels. (a) Induction of Bim $\mathrm{EL}_{\mathrm{L}}$ expression in Mel-RM.Bim cells that carried a lentivirusbased 4-OHT-responsive inducible Bim $\mathrm{EL}_{\mathrm{L}}$ expression system. Mel-RM cells and Mel-RM.Bim cells were treated with 4-OHT (10 nM), TM ( $\left.3 \mu \mathrm{M}\right)$, or 4-OHT plus TM for $24 \mathrm{~h}$. Thirty microgram of total protein of whole-cell lysates were then subjected to western blot analysis of Bim and GAPDH (as a loading control). The data shown are representative of three individual western blot analyses. (b) Induction of Bim $\mathrm{EL}_{\mathrm{L}}$ sensitizes Mel-RM.Bim to TM-induced apoptosis. Mel-RM cells and Mel-RM.Bim cells that carried a lentivirus-based 4-OHT-responsive inducible Bim $\mathrm{EL}_{\mathrm{L}}$ expression system were treated with 4-OHT (10 nM), TM $(3 \mu \mathrm{M})$, or 4-OHT plus TM for 48 h. Apoptosis was measured by the PI method using flow cytometry. The data shown are the mean \pm S.E. of three individual experiments. (c) Overexpression of Bim $\mathrm{EL}_{\mathrm{L}}$ in $\mathrm{IgR3}$ and MM200 cells transiently transfected with $\mathrm{CDNA}$ encoding Bim $\mathrm{EL}$. IgR3 and MM200 cells were transfected with vector alone or Bim $\mathrm{EL} \mathrm{CDNA}$. Twenty-four hours later, cells were treated with $\mathrm{TM}(3 \mu \mathrm{M})$ for a further $24 \mathrm{~h}$. Thirty microgram of total protein of whole-cell lysates were then subjected to western blot analysis of Bim and GAPDH (as a loading control). The data shown are representative of three individual western blot analyses. (d) Overexpression of Bim sensitizes IgR3 and MM200 cells to ER stress-induced apoptosis. IgR3 (left) and MM200 (right) cells were transfected with vector alone or Bim $\mathrm{EL}_{\mathrm{C}} \mathrm{CDNA}$. Twenty-four hours later, cells were treated with TM $(3 \mu \mathrm{M})$ for a further $48 \mathrm{~h}$. Apoptosis was measured by the PI method using flow cytometry. The data shown are the mean \pm S.E. of three individual experiments

types of cells undergoing ER stress. ${ }^{6}$ Indeed, treatment of Mel-RM cells with the pharmacological PP2A activator, FTY720 (fingolimod), ${ }^{15}$ resulted in upregulation of Bim $\mathrm{EL}_{\text {in }}$ melanoma cells undergoing ER stress (Figure 5a and Supplementary Figure 7), whereas treatment with okadaic acid $(\mathrm{OA})$ at a concentration that specifically inhibits PP2A led to increased phosphorylation of Bim $\mathrm{EL}_{\mathrm{L}}$ (Figures $5 \mathrm{~b}$ and c), ${ }^{6}$ indicating that PP2A has the similar regulatory effect on the Bim $\mathrm{EL}_{\mathrm{L}}$ expression in melanoma cells as in other cell types. ${ }^{6}$ Nevertheless, phosphorylation of Bim was increased in melanoma cells undergoing ER stress (Figures 1a, b, d and 4c), suggesting that PP2A activity is repressed by ER stress in melanoma cells. This was confirmed by reduction in the phosphatase activity of PP2A in melanoma cells after treatment with $\mathrm{TM}$, which was in contrast to the moderate increase in PP2A activity in MCF-7 cells induced by the same treatment (Figure $5 d$ ).

We monitored the expression of the catalytic $C$ subunit of PP2A in Mel-RM in comparison with MCF-7 cells undergoing ER stress. Strikingly, PP2A-C was progressively downregulated in Mel-RM cells, whereas it was markedly increased in MCF-7 cells, after treatment with TM (Figure 5e). Downregulation of PP2A-C was also observed in another two melanoma lines (Figure $5 \mathrm{e}$ ). The role of downregulation of PP2A-C in reduction of PP2A activity in melanoma cells under
ER stress was confirmed by transfection of a PP2A-Cexpressing construct into Mel-RM cells, which showed that overexpression of PP2A-C caused an increase in PP2A activity and upregulation of $\mathrm{Bim}_{\mathrm{EL}}$ in cells with or without treatment with TM, and enhanced ER stress-induced apoptosis (Figures $5 f$ and $g$, and Supplementary Figure 8).

Dephosphorylation of ERK is necessary for PP2Amediated inhibition of Bim $\mathrm{EL}_{\mathrm{L}}$ phosphorylation in melanoma cells. Interestingly, treatment with FTY720 or overexpression of PP2A-C downregulated ERK phosphorylation, whereas exposure to $\mathrm{OA}$ caused an increase in the phosphorylated ERK (pERK) levels (Figures 5a, b and f), suggesting that PP2A has a role in dephosphorylating ERK in melanoma cells. In contrast, neither FTY720 nor OA caused noticeable changes in the ERK phosphorylation status in MCF-7 cells (Figures $5 a$ and b). These results raised a possibility that dephosphorylation of ERK may have an

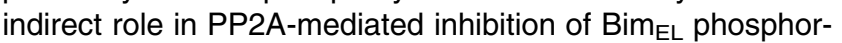
ylation in melanoma cells, ${ }^{7,8}$ even though it is known that PP2A directly targets Bim $\mathrm{EL}_{\text {for }}$ dephosphorylation in MCF-7 cells and other types of cells. ${ }^{6}$

Although the role of MEK/ERK signaling in phosphorylation of $\mathrm{Bim}_{\mathrm{EL}}$ in melanoma cells under ER stress had been established by inhibition of MEK with U0126 and siRNA 
knockdown of MEK1 (Figures 4e and f), we sought to further clarify the role of dephosphorylation of ERK in PP2Amediated inhibition of Bim phosphorylation in melanoma cells by knocking down ERK1/2 with siRNA in Mel-RM cells. As knockdown of ERK1/2 alone markedly inhibited phosphoryla-

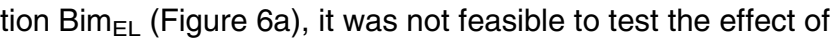
combination of activation of PP2A and knockdown of ERK1/2

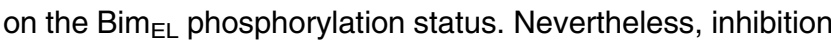
of ERK by siRNA partially blocked phosphorylation of Bim induced by $O A$, in particular, in the presence of TM (Figure 6a), suggesting that PP2A-mediated dephosphorylation of Bim is associated with its dephosphorylating effect on ERK. Consistently, treatment of melanoma cells with U0126 attenuated phosphorylation of $\mathrm{Bim}_{\mathrm{EL}}$ by OA (Figure $6 \mathrm{~b}$ ). Of note, OA partially restored the levels of pERK in Mel-RM cells with ERK knockdown by siRNA, suggesting that the minimal residue of ERK was phosphorylated when PP2A was inhibited (Figure 6a). Similarly, OA caused partial recovery in ERK phosphorylation in melanoma cells treated with U0126 (Figure 6b). These results further substantiate the effect of PP2A on dephosphorylation of ERK in melanoma cells.
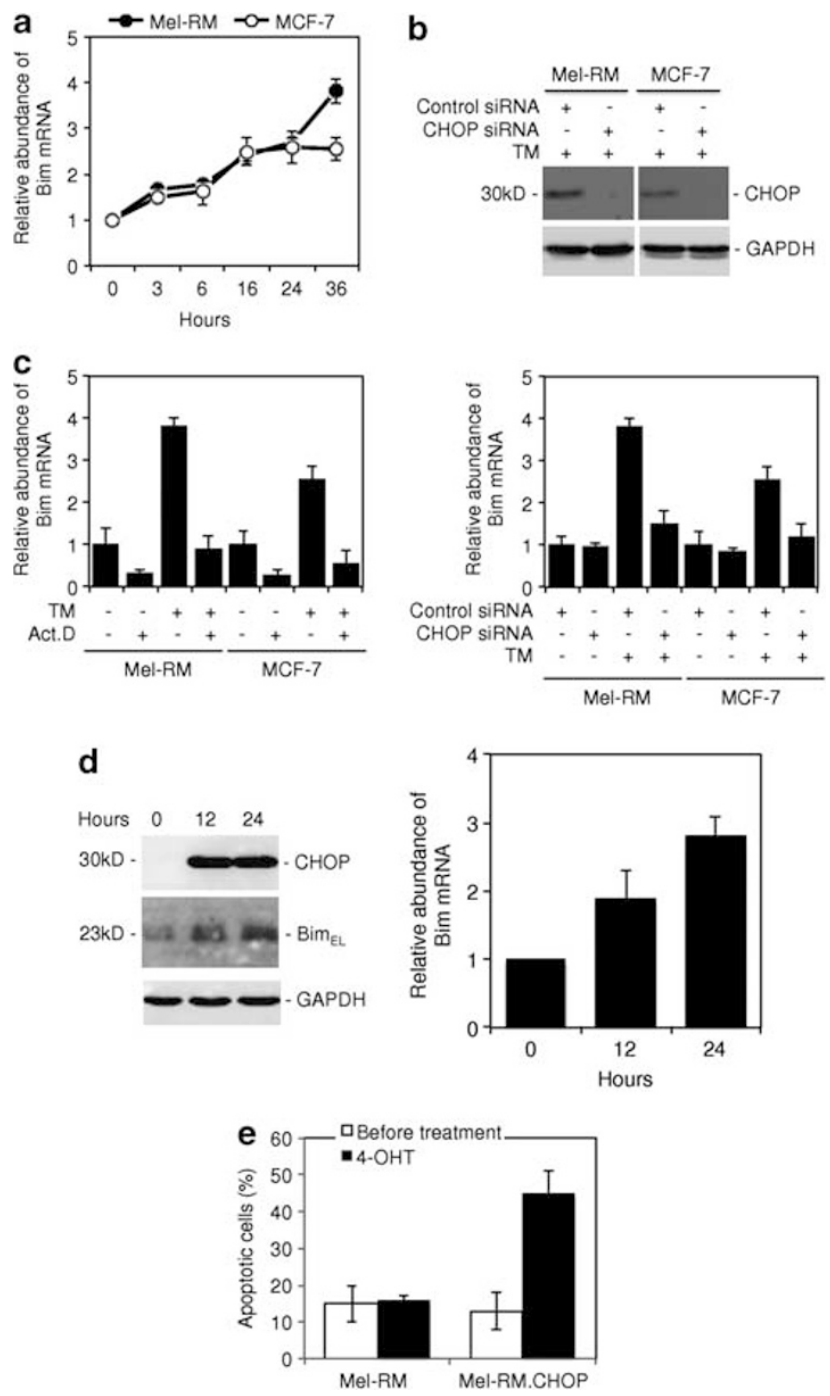

PP2A is physically associated with ERK but not Bim in melanoma cells. PP2A exerts its phosphatase effect by physical interaction with its substrates. ${ }^{20,21}$ We therefore examined the potential physical association of PP2A with ERK and Bim $\mathrm{EL}_{\mathrm{L}}$ in melanoma cells in comparison with MCF-7 cells. Strikingly, although $\mathrm{Bim}_{\mathrm{EL}}$ was readily co-precipitated with PP2A-C in protein extracts from MCF-7 cells under ER stress, no Bim $\mathrm{EL}_{\mathrm{L}}$ was detected in PP2A-C precipitates from Mel-RM cells with or without treatment with TM (Figure 6c). In contrast, little ERK was co-precipitated with PP2A in MCF-7 cells, but it was readily co-precipitated with PP2A in Mel-RM cells with or without undergoing ER stress (Figure 6d). These results further suggest that, in contrast to dephosphorylating Bim directly, ${ }^{6}$ PP2A inhibits phosphorylation of Bim indirectly through dephosphorylating ERK in melanoma cells.

\section{Discussion}

Past studies have shown that upregulation of the antiapoptotic protein $\mathrm{Mcl}-1$ is critical for survival of melanoma

Figure 3 ER stress induces transcriptional upregulation of Bim in melanoma cells. (a) TM induces sustained upregulation of Bim mRNA in melanoma cells. Mel-RM melanoma cells and MCF-7 breast cancer cells were treated with TM $(3 \mu \mathrm{M})$ for indicated periods before total RNA was isolated and subjected to qPCR analysis for the Bim mRNA expression. The relative abundance of the Bim mRNA in each cell line before treatment was arbitrarily designated as 1 . The data shown are the mean \pm S.E. of three individual experiments. (b) $\mathrm{CHOP}$ is required for transcriptional upregulation of Bim by ER stress in melanoma cells. Upper panel: Mel-RM melanoma cells and MCF-7 breast cancer cells were transfected with the control or CHOP siRNA. Twenty-four hours later, cells were treated with TM $(3 \mu \mathrm{M})$ for a further $6 \mathrm{~h}$. Thirty microgram of total protein of whole-cell lysates were then subjected to western blot analysis of CHOP and GAPDH (as a loading control). The data shown are representative of three individual western blot analyses. Lower panel: Mel-RM melanoma cells and MCF-7 breast cancer cells were transfected with the control or CHOP siRNA. Twenty-four hours later, cells were treated with TM $(3 \mu \mathrm{M})$ for a further $36 \mathrm{~h}$ before total RNA was isolated and subjected to $\mathrm{gPCR}$ analysis for the Bim mRNA expression. The relative abundance of the Bim mRNA in each cell line transfected with the control siRNA without treatment was arbitrarily designated as 1 . The data shown are the mean \pm S.E. of three individual experiments. (c) The general transcription inhibitor actinomycin D (Act.D) efficiently blocks transcriptional upregulation of Bim in Mel-RM melanoma cells and MCF-7 breast cancer cells. Mel-RM and MCF-7 cells were treated with Act.D (100 ng/ml) for $1 \mathrm{~h}$ before the addition of TM $(3 \mu \mathrm{M})$ for a further $24 \mathrm{~h}$. Total RNA was then isolated and subjected to $\mathrm{qPCR}$ analysis for the Bim mRNA expression. The relative abundance of the Bim mRNA in each cell line before treatment was arbitrarily designated as 1 . The data shown are the mean \pm S.E. of three individual experiments. (d) Overexpression of CHOP induces upregulation of the Bim mRNA and the Bim $m_{E L}$ protein in melanoma cells. Left panel: Mel-RM.CHOP cells that carried a lentivirus-based 4-OHT-responsive inducible $\mathrm{CHOP}$ expression system were treated with $4-\mathrm{OHT}(10 \mathrm{nM})$ for indicated periods. Thirty microgram of total protein of whole-cell lysates were then subjected to western blot analysis of $\mathrm{CHOP}$, $\mathrm{Bim}$, and GAPDH (as a loading control). The data shown are representative of three individual western blot analyses. Right panel: Mel-RM.CHOP cells that carried a lentivirus-based 4-OHT-responsive inducible CHOP expression system were treated with $4-\mathrm{OHT}(10 \mathrm{nM})$ for indicated periods. Total RNA was isolated and subjected to $\mathrm{qPCR}$ analysis for the Bim mRNA expression. The relative abundance of the Bim mRNA in cells without 4-OHT treatment was arbitrarily designated as 1. The data shown are the mean $\pm S . E$. of three individual experiments. (e) Overexpression of CHOP induces apoptosis in melanoma cells. Mel-RM.CHOP cells that carried a lentivirus-based 4-OHT-responsive inducible $\mathrm{CHOP}$ expression system were treated with $4-\mathrm{OHT}(10 \mathrm{nM})$ for $48 \mathrm{~h}$ before apoptosis was measured by the PI method using flow cytometry. The data shown are the mean \pm S.E. of three individual experiments 

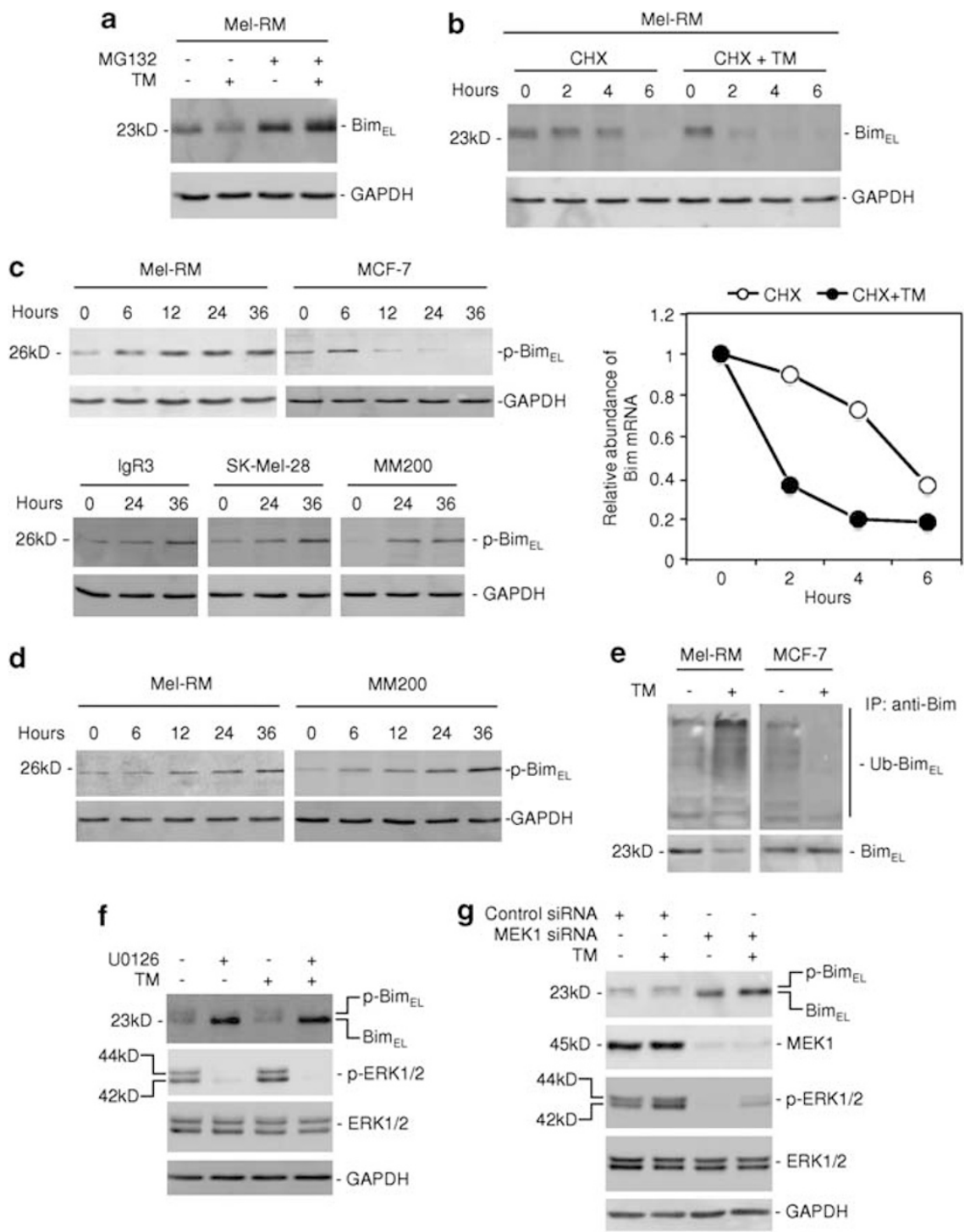

Figure 4 Downregulation of the Bim $\mathrm{EL}_{\mathrm{L}}$ protein in melanoma cells undergoing ER stress is mediated by MEK/ERK signaling. (a) The proteasome inhibitor MG132 reverses downregulation of the Bim $\mathrm{EL}_{\mathrm{L}}$ in melanoma cells under ER stress. Mel-RM cells with or without pretreatment with the proteasome inhibitor MG132 (10 $\left.\mu \mathrm{M}\right)$ for $1 \mathrm{~h}$ were treated with TM $(3 \mu \mathrm{M})$ for $24 \mathrm{~h}$. Thirty microgram of total protein of whole-cell lysates were then subjected to western blot analysis of Bim and GAPDH (as a loading control). The data shown are representative of three individual experiments. (b) ER stress accelerates the turnover rate of Bim $\mathrm{EL}_{\mathrm{L}}$ in melanoma cells. Upper panel: Mel-RM cells were treated with the protein synthesis inhibitor cycloheximide $(\mathrm{CHX})(10 \mu \mathrm{g} / \mathrm{ml})$ with or without the addition of TM $(3 \mu \mathrm{M})$ for indicated periods. Thirty microgram of total protein of whole-cell lysates were then subjected to western blot analysis of Bim and GAPDH (as a loading control). The data shown are representative of three individual experiments. Lower panel: quantitative expression levels of Bim $\mathrm{EL}_{\mathrm{L}}$ as shown the upper panel that were normalized to GAPDH. Quantitation of each band was determined using ImageReader LAS-4000. The data shown are representative of three individual experiments. (c) TM phosphorylates Bim $\mathrm{EL}_{\mathrm{L}}$ in melanoma cells but dephosphorylates it in MCF-7 cells. Mel-RM and MCF-7 (upper panel) and IgR3, Sk-Mel-28, and MM200 (lower panel) cells were treated TM $(3 \mu \mathrm{M})$ for indicated periods. Thirty microgram of total protein of whole-cell lysates were then subjected to western blot analysis using an antibody that specifically recognizes Bim EL phosphorylated at Ser69. Western blot analysis of GAPDH was included as a loading control. The data shown are representative of three individual experiments. (d) TG induces phosphorylation of Bim $\mathrm{EL}_{\mathrm{L}}$ in melanoma cells. Mel-RM and MM200 cells were treated with TG $(1 \mu \mathrm{M})$ for indicated periods. Thirty microgram of total protein of whole-cell lysates were then subjected to western blot analysis using an antibody that specifically recognizes Bim $\mathrm{EL}_{\mathrm{L}}$ phosphorylated at Ser69. Western blot analysis of GAPDH was included as a loading control. The data shown are representative of three individual experiments. (e) TM increases an increase in ubiquitination of Bim $\mathrm{EL}_{\mathrm{L}}$ in Mel-RM melanoma cells, but a decrease in MCF-7 breast cancer cells. Whole-cell lysates from Mel-RM melanoma cells and MCF-7 breast cancer cells with or without treatment with TM $(3 \mu \mathrm{M})$ for $36 \mathrm{~h}$ were subjected to immunoprecipitation using an antibody against Bim. Thirty microgram of total protein of the resulting precipitates were subjected to SDS-PAGE and probed with an antibody against ubiquitin and an antibody against $\mathrm{Bim}$. The data shown are representative of three individual experiments. (f) The MEK inhibitor U0126 inhibits phosphorylation of Bim $\mathrm{EL}_{\mathrm{L}}$ and increases its expression in melanoma cells undergoing ER stress. Thirty microgram of total protein of whole-cell lysates from Mel-RM cells treated with U0126 (20 $\mu \mathrm{M})$, TM ( $3 \mu \mathrm{M})$, or U0126 plus TM for $24 \mathrm{~h}$ were subjected to western blot analysis of Bim, pERK, ERK, and GAPDH (as a loading control). The data shown are representative of three individual experiments. (g) Knockdown of MEK1 by siRNA inhibits phosphorylation of Bim ${ }_{E L}$ and increases its expression in melanoma cells undergoing ER stress. Mel-RM cells were transfected with the control or MEK1 siRNA. Twenty-four hours later, cells were treated with $\mathrm{TM}(3 \mu \mathrm{M})$ for a further $24 \mathrm{~h}$. Thirty microgram of total protein of whole-cell lysates were then subjected to western blot analysis of Bim, MEK1, pERK (pERK), ERK, and GAPDH (as a loading control). The data shown are representative of three individual western blot analyses 

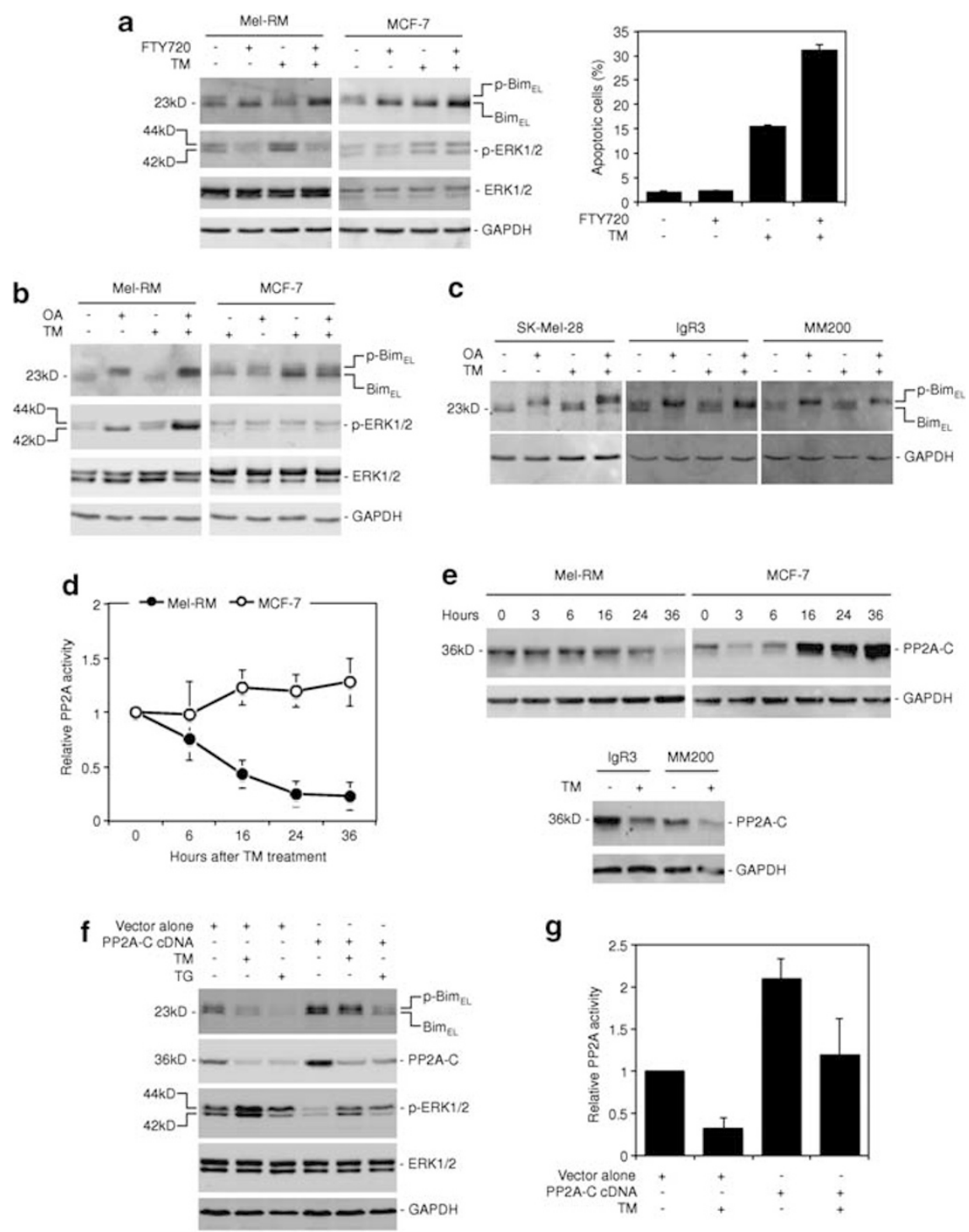

Figure 5 Downregulation of the Bim $E L$ protein in melanoma cells under ER stress is associated with reduction in PP2A activity that is, at least in part, due to downregulation of the PP2A catalytic $C$ subunit (PP2A-C). (a) Pharmacological activation of PP2A reverses downregulation of Bim $\mathrm{EL}_{\mathrm{L}}$ by ER stress in melanoma cells. Left panel: $30 \mu \mathrm{g}$ of total protein of whole-cell lysates from Mel-RM melanoma cells or MCF-7 breast cancer cells treated with the pharmacological PP2A activator FTY720 $(2.5 \mu \mathrm{M})$, TM $(3 \mu \mathrm{M})$, or FTY720 plus TM for $24 \mathrm{~h}$ were subjected to western blot analysis of Bim, pERK, ERK, and GAPDH (as a loading control). The data shown are representative of three individual experiments. Right panel: Mel-RM cells were treated with FTY720 $(2.5 \mu \mathrm{M})$, TM $(3 \mu \mathrm{M})$, or FTY720 plus TM for $48 \mathrm{~h}$ before apoptosis was measured by the PI method using flow cytometry. The data shown are the mean \pm S.E. of three individual experiments. (b) Inhibition of PP2A further promotes phosphorylation of Bim $\mathrm{EL}_{\mathrm{L}}$ and increases phosphorylation of ERK in Mel-RM cells under ER stress. Thirty microgram of total protein of whole-cell lysates from Mel-RM melanoma cells or MCF-7 breast cancer cells treated with the OA $(50 \mathrm{nM})$, TM $(3 \mu \mathrm{M})$, or OA plus TM for $24 \mathrm{~h}$ were subjected to western blot analysis of Bim, pERK, ERK, and GAPDH (as a loading control). The data shown are representative of three individual experiments. (c) Inhibition of PP2A further promotes phosphorylation of Bim $\mathrm{EL}_{\mathrm{L}}$ in Sk-Mel28, IgR3, and MM200 melanoma cells. Thirty microgram of total protein of whole-cell lysates from Sk-Mel-28, IgR3, and MM200 cells treated with the OA (50 nM), TM ( $3 \mu \mathrm{M}$ ), or OA plus TM for $24 \mathrm{~h}$ were subjected to western blot analysis of Bim and GAPDH (as a loading control). The data shown are representative of three individual experiments. (d) ER stress reduces PP2A activity in Mel-RM melanoma cells, but increases PP2A activity in MCF-7 breast cancer cells. Mel-RM cells and MCF-7 cells were treated with TM $(3 \mu \mathrm{M})$ for indicated periods before the phosphatase activity of PP2A was quantitated using a PP2A-C immunoprecipitation phosphatase assay kit. The PP2A phosphatase activity in cells without treatment was arbitrarily designated as 1 . The data shown are the mean $\pm S$.E. of three individual experiments. (e) ER stress downregulates PP2A-C in melanoma cells but upregulates its expression in MCF-7 breast cancer cells. Upper panel: Thirty microgram of total protein of whole-cell lysates from Mel-RM melanoma cells or MCF-7 breast cancer cells treated with TM $(3 \mu \mathrm{M})$ for indicated periods were subjected to western blot analysis of PP2A-C and GAPDH (as a loading control). The data shown are representative of three individual experiments. Lower panel: Thirty microgram of total protein of whole-cell lysates from lgR3 and MM200 melanoma cells treated with TM $(3 \mu \mathrm{M})$ for $24 \mathrm{~h}$ were subjected to western blot analysis of PP2A-C and GAPDH (as a loading control). The data shown are representative of three individual experiments. (f) Overexpression of PP2A-C upregulates Bim $\mathrm{EL}_{\mathrm{EL}}$ and decrease ERK phosphorylation in melanoma cells. Mel-RM cells were transiently transfected with vector alone or CDNA encoding PP2A-C. Twenty-four hours later, cells were treated with TM $(3 \mu \mathrm{M})$ or TG $(1 \mu \mathrm{M})$ for a further $24 \mathrm{~h}$. Thirty microgram of total protein of whole-cell lysates were then subjected to western blot analysis of Bim, PP2A-C, pERK, ERK, and GAPDH (as a loading control). The data shown are representative of three individual western blot analyses. (g) Overexpression of PP2A-C causes increased PP2A activity in melanoma cells with or without undergoing ER stress. Mel-RM cells were transiently transfected with vector alone or CDNA encoding PP2A-C. Twenty-four hours later, cells were treated with TM $(3 \mu \mathrm{M})$ for a further $24 \mathrm{~h}$. The phosphatase activity of PP2A was then quantitated using a PP2A-C immunoprecipitation phosphatase assay kit. The PP2A phosphatase activity in cells transfected with vector alone without TM treatment was arbitrarily designated as 1 . The data shown are the mean \pm S.E. of three individual experiments 

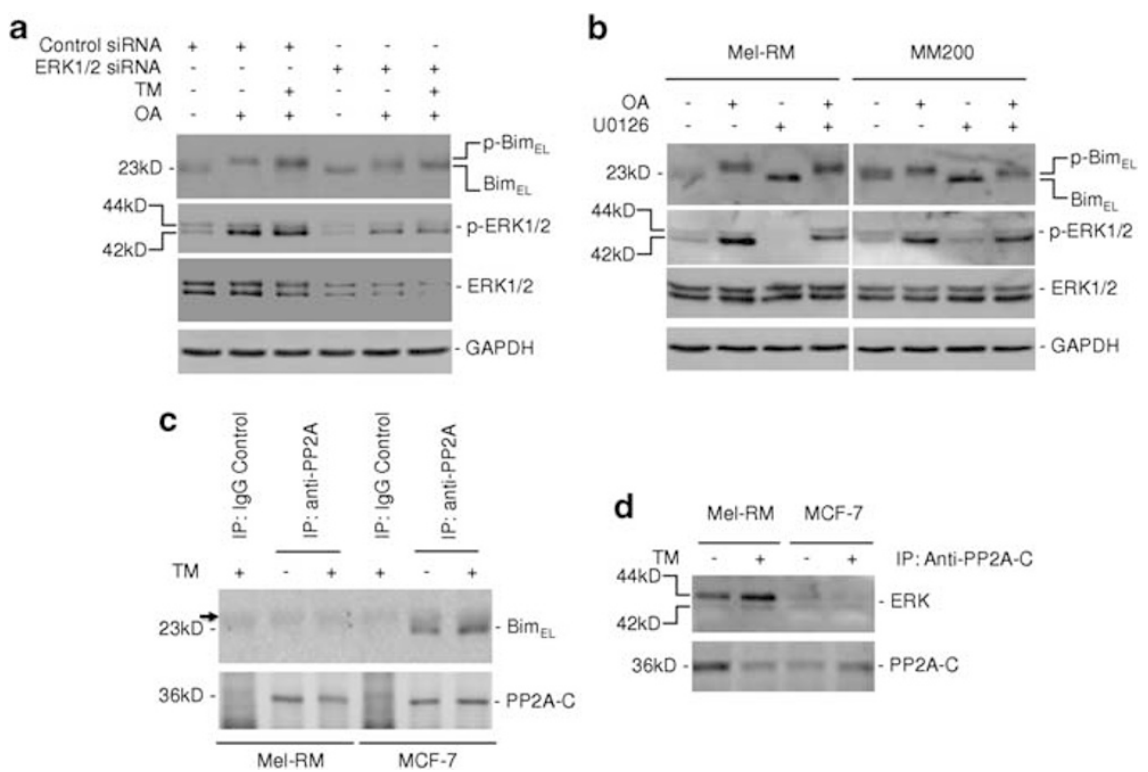

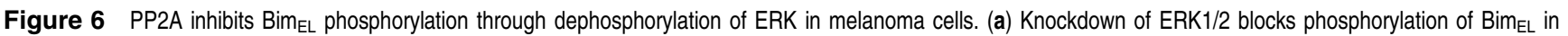
melanoma cells with or without undergoing ER stress. Mel-RM cells were transfected with the control siRNA or ERK1 siRNA plus ERK2 siRNA. Twenty-four hours later, cells were treated with $\mathrm{OA}(50 \mathrm{nM})$ for $24 \mathrm{~h}$ in the presence or absence of TM $(3 \mu \mathrm{M})$. Thirty microgram of total protein of whole-cell lysates were then subjected to western blot analysis of Bim, pERK, ERK, and GAPDH (as a loading control). The data shown are representative of three individual western blot analyses. (b) The MEK inhibitor U0126 blocks phosphorylation of Bim $\mathrm{EL}_{\mathrm{L}}$ mediated by OA in melanoma cells. Thirty microgram of total protein of whole-cell lysates from Mel-RM and MM200 cells treated with OA $(50 \mathrm{nM}), \mathrm{U} 0126(20 \mu \mathrm{M})$, or OA plus U0126 for $24 \mathrm{~h}$ were subjected to western blot analysis of Bim, pERK, ERK, and GAPDH (as a loading control). The data shown are representative of three individual experiments. (c) PP2A-C is physically associated with Bim $\mathrm{EL}_{\mathrm{L}}$ in MCF-7 breast cancer cells but not in melanoma cells. Whole-cell lysates from Mel-RM melanoma cells with or without treatment with TM $(3 \mu \mathrm{M})$ for $6 \mathrm{~h}$ and those from MCF-7 breast cancer cells with or without treatment with TM $(3 \mu \mathrm{M})$ for $16 \mathrm{~h}$ were subjected to immunoprecipitation with a mouse antibody against PP2A-C. Immunoprecipitation of whole-cell lysates from cells treated with TM with purified mouse IgG was included as a control. Thirty microgram of total protein of the resulting precipitates were subjected to SDS-PAGE and probed with an antibody against Bim and an antibody against PP2A-C. The data shown are representative of three individual experiments. (d) PP2A-C is physically associated with ERK in melanoma cells but not in MCF-7 breast cancer cells. Whole-cell lysates from Mel-RM melanoma cells and MCF-7 breast cancer cells with or without treatment with TM $(3 \mu \mathrm{M})$ for $6 \mathrm{~h}$ were subjected for immunoprecipitation with a mouse antibody against PP2A-C. Thirty microgram of total protein of the resulting precipitates were subjected to SDS-PAGE and probed with an antibody against ERK and an antibody against PP2A-C. The data shown are representative of three individual experiments

cells upon ER stress. ${ }^{14}$ When Mcl-1 is inhibited, ER stress induces apoptosis of melanoma cells by activation of the BH3-only proteins Noxa and PUMA, whereas Bim, which is responsible for induction of apoptosis by ER stress in many other cell types, is not involved. ${ }^{14}$ Nevertheless, Bim has an important role in killing of melanoma cells by other apoptotic stimuli such as histone deacetylase inhibitors and inhibitors of the RAF/MEK/ERK pathway. ${ }^{19,22,23}$ These results collectively suggest that Bim is suppressed in melanoma cells under ER stress. In this study, we identify reduction in PP2A activity as an important mechanism to keep Bim $\mathrm{EL}_{\mathrm{L}}$ in check by enhancing its post-translational degradation in melanoma cells subjected to pharmacological ER stress inducers.

We found that, in agreement with observations in a number of other cell types including MCF-7 cells, the Bim transcript was increased in melanoma cells by ER stress through the transcription factor $\mathrm{CHOP} .{ }^{6}$ However, in contrast to the sustained increase in the Bim mRNA, the Bim $\mathrm{EL}_{\mathrm{L}}$ protein was downregulated after an initial increase in melanoma cells upon ER stress. This downregulation was important in protection of melanoma cells, as ER stress induced markedly increased apoptosis when Bim was overexpressed. These results, along with our previous finding that PUMA and Noxa that are upregulated in melanoma cells upon ER stress are inhibited by $\mathrm{Mcl}-1,{ }^{9}$ demonstrated that melanoma cells have developed multiple mechanisms to maintain the balance between pro- and anti-apoptotic Bcl-2 family proteins to survive ER stress. ${ }^{14,15,24,25}$

Downregulation of Bim at the protein level despite the sustained increase in its transcript mediated by CHOP is specific to melanoma cells under ER stress, as overexpression of $\mathrm{CHOP}$ resulted in upregulation of the Bim mRNA as well as the Bim $\mathrm{EL}_{\mathrm{L}}$ protein. It appears therefore that in response to ER stress, melanoma cells activate a powerful posttranscriptional mechanism(s) leading to robust suppression of the Bim $_{\mathrm{EL}}$ protein expression. Indeed, proteasomal degradation of the Bim $\mathrm{EL}_{\mathrm{L}}$ protein was accelerated in melanoma cells treated with TM. This was in sharp contrast to the observation in MCF-7 cells in which the half-life time of the protein was prolonged upon ER stress. ${ }^{6}$ Consistently, although phosphorylation and ubiquitination of Bim $\mathrm{EL}_{\mathrm{L}}$ were reduced in MCF-7 cells, ${ }^{6}$ these post-translational modifications of the protein were enhanced in melanoma cells under ER stress.

$B_{E L}$ can be phosphorylated by protein kinases such as ERK and JNK and dephosphorylated by the PP2A. ${ }^{7,8}$ The latter is of particular importance in cells under ER stress as PP2A-mediated dephosphorylation of Bim has an essential role in upregulation of Bim in many types of cells undergoing ER stress. ${ }^{6}$ Strikingly, while ERK activation was increased and had an essential role in phosphorylation of $\mathrm{Bim}_{\mathrm{EL}}$ in 
melanoma cells subjected to ER stress, the phosphatase activity of PP2A was reduced by ER stress in melanoma cells. This suggests that the increased phosphorylation and subsequent proteasomal degradation of $\mathrm{Bim}_{\mathrm{EL}}$ in melanoma cells under ER stress is caused by the predominant phosphorylating effect of ERK that overrides the dephosphorylating effect of PP2A on the protein. We did not observe a role of JNK in phosphorylation of Bim by ER stress in melanoma cells (data not shown), but whether other protein kinases such as PKA are involved remains to be defined. ${ }^{26,27}$

ER stress-triggered reduction in PP2A activity seems to be highly specific to melanoma cells in that PP2A activity is increased in many other cell types by ER stress. ${ }^{6,28,29}$ In the search for the mechanism(s) responsible for the differential regulation of PP2A by ER stress, we found that PP2A-C was progressively decreased in melanoma cells, but markedly increased in MCF-7 cells, after treatment with TM. Introduction of a PP2A-C-expressing construct increased PP2A activity not only in healthy melanoma cells, but also in those subjected to ER stress, indicating that downregulation of PP2A-C is responsible, at least in part, for suppression of PP2A activity in melanoma cells. Similar to the pharmacological PP2A activator, overexpression of PP2A-C reversed downregulation of $\mathrm{Bim}_{\mathrm{EL}}$ in melanoma cells under ER stress, confirming the importance of reduction in PP2A activity in ER stress-induced suppression of Bim in melanoma cells.

$A$ question remaining unaddressed is how PP2A-C is selectively downregulated by ER stress in melanoma cells. Similarly, it is unclear whether additional mechanisms such as possible alterations in the expression of other PP2A subunits are involved in regulating PP2A activity in cells undergoing ER stress. Mutations have been identified in different components of the PP2A complex, which have been linked to a variety of human cancers. ${ }^{11-13}$ In particular, a truncated form of PP2A-B56 $\gamma$ has been found in the mouse melanoma cell line B16 that is not able to dephosphorylate specific targets and has a role in malignant progression. ${ }^{13}$ Although no mutations have been found in patients, the expression of the $P P 2 A-B 56 \gamma$ gene is frequently reduced in human melanoma compared to naevi. ${ }^{30}$ Similarly, PP2A-B56 $\alpha$ has recently been shown to be expressed at lower levels in metastatic compared with primary melanomas. ${ }^{31}$ Regardless, our results clearly demonstrated that reduction in PP2A activity associated with downregulation of PP2A-C is an important mechanism triggered by ER stress in melanoma cells to suppress the Bim $_{\mathrm{EL}}$ expression. Notably, despite the reduction in its activity, PP2A retained part of its dephosphorylating effect on Bim, in that treatment with $O A$ caused an increase in Bim $\mathrm{EL}_{\mathrm{L}}$ phosphorylation in melanoma cells treated with TM. Nevertheless, this residual effect was apparently not adequate to supersede the phosphorylating effect of ERK on Bim $\mathrm{EL}_{\mathrm{L}}$ to accumulate the protein to such a level required for efficient induction of apoptosis.

Activation of the MEK/ERK pathway has been well documented to protect cells from ER stress-induced apoptosis. ${ }^{25,32}$ However, how ER stress triggers activation of the pathway remains undefined. We found that the increase in ERK activation in melanoma cells under ER stress was closely associated reduction in PP2A activity, which otherwise directly targets ERK for dephosphorylation. This was demonstrated by (1) activation of PP2A by FTY720 or overexpression of PP2A-C caused downregulation of pERK in melanoma cells with or with being subjected to ER stress; (2) inhibition of PP2A by OA upregulated ERK phosphorylation, in particular, in melanoma cells treated with TM; and (3) ERK was readily co-precipitated with PP2A-C in melanoma cells with or without subjected to ER stress. In contrast, we did not observe any noticeable effect of PP2A on ERK activation in MCF-7 cells. On the other hand, although PP2A directly targets Bim for dephosphorylation in MCF-7 and a number of other types of cells undergoing ER stress, ${ }^{6}$ it did not appear to directly act on Bim in melanoma cells with or without subject to ER stress. Instead, the inhibitory effect of PP2A on Bim phosphorylation was mediated indirectly by its dephosphorylating effect on ERK. This was suggested by reduced phosphorylation of Bim $\mathrm{EL}_{\mathrm{L}}$ mediated by OA when ERK was inhibited, and was further supported by the lack of physical association between Bim $\mathrm{EL}_{\mathrm{L}}$ and PP2A in melanoma cells. It is known that the $B$ subunit in the PP2A heterotrimeric complex dictates the substrate specificity of PP2A, and that the dynamic exchange of PP2A-B in the complex is regulated by reversible methylation and phosphorylation of the C-terminal tail of the $\mathrm{C}$ subunit, involving the PP2A specific methyelsterase PME1 and methyltransferase, LCMT1. ${ }^{9,10}$ It is conceivable that the differential effects of PP2A on ERK and Bim are associated with cell type- and context-dependent recruitment of different $B$ subunits into the PP2A heterotrimeric complex, but the mechanism responsible for this remains to be defined. . $^{9,10,33,34}$

In conclusion, we have shown in this study that reduction in PP2A activity is an important mechanism responsible for activation of $\mathrm{ERK}$, downregulation of $\mathrm{Bim}_{\mathrm{EL}}$, and resistance to apoptosis in melanoma cells undergoing ER stress. This reduction is, at least in part, due to downregulation of PP2A-C. Moreover, we have demonstrated that the inhibitory effect of $\mathrm{PP} 2 \mathrm{~A}$ on $\mathrm{Bim}_{\mathrm{EL}}$ phosphorylation is predominantly mediated by its dephosphorylating effect on ERK (Supplementary Figure 9). These results suggest that pharmacological activation of PP2A may improve treatment results of agents that induce ER stress in melanoma cells such as cisplatin and sorafenib. ${ }^{35,36}$ In addition, the dephosphorylating effect of PP2A on ERK in melanoma cells may also have important implications in improving efficacy of targeting the RAF/MEK/ ERK pathway, which is a promising strategy in the treatment of metastatic melanoma. ${ }^{37,38}$

\section{Materials and Methods}

Cell lines. The human melanoma cell lines Mel-RM, MM200, IgR3, and SK-Mel-28 and the human breast cancer cell line MCF-7 were described previously. ${ }^{14,39}$ They were cultured in Dulbecco's modified Eagle medium supplemented with $5 \%$ fetal calf serum (Commonwealth Serum Laboratories, Melbourne, VIC, Australia).

Antibodies, recombinant proteins, and other reagents. The rabbit polyclonal antibodies (pAbs) against Bim was supplied by Imgenex (San Diego, CA, USA); the mouse monoclonal antibodies (mAbs) against CHOP, pERK, $\mathrm{Mcl}-1$, and $\mathrm{Bcl}-\mathrm{X}_{\mathrm{L}}$ and the rabbit pAb against GRP78 were from Santa Cruz Biotechnology (Santa Cruz, CA, USA); the rabbit pAbs against phosphorylated Bim, ERK, Bid, and PUMA and the mouse mAbs against ubiquitin were from Cell Signaling Technology (Beverly, MA, USA); the mouse mAb against GAPDH was from Ambion (Austin, TX, USA). The restriction enzyme ApaLI was purchased from New England Biolabs (Ipswich, MA, USA). The PP2A inhibitor OA, 
Actinomycin D, TM, and TG were purchased from Sigma-Aldrich (St. Louis, MO, USA). The PP2A activator FTY720 and MG132 were from Cayman Chemicals (Ann Arbor, MI, USA). The MEK inhibitor U0126 was from Promega (Madison, WI, USA). Cycloheximide was purchased from Calbiochem (La Jolla, CA, USA).

Apoptosis analysis. Apoptotic cells were quantified by measurement of sub-G1 DNA content using propidium iodide (PI) on a flow cytometer (Becton Dickinson, Sunnyvale, CA, USA) as described elsewhere. ${ }^{40}$

Western blot analysis. Western blot analysis was carried out as described previously. ${ }^{40}$ Labeled bands were detected by Luminata Crescendo Western HRP substrate (Millipore, Billerica, MA, USA) and images were captured and the intensity of the bands was quantitated with ImageReader LAS-4000 (Fujifilm Corporation, Tokyo, Japan).

Immunoprecipitation. Immunoprecipitation experiments were carried out as described previously. ${ }^{40}$

PP2A phosphatase activity assay. PP2A activity was determined using the PP2A immunoprecipitation phosphatase assay kit (Millipore). Briefly, whole-cell lysates in $50 \mathrm{nM}$ Tris/ $\mathrm{HCl} \mathrm{pH} 7.4,150 \mathrm{mM} \mathrm{NaCl}, 1 \mathrm{mM}$ EDTA, and 1\% NP40 were incubated for $2 \mathrm{~h}$ at $4{ }^{\circ} \mathrm{C}$ with $4 \mathrm{mg}$ of an antibody against PP2A-C and protein A-agarose. After three washes, immunoprecipitates were used in a phosphoatase reaction according to the manufacturer's instructions. As an internal control, the specificity of the reaction was assessed by inhibiting PP2A activity with $1 \mathrm{nM}$ $\mathrm{OA}$ before titration. The percentage of phosphatase activity was determined by dividing the free phosphate of the test cells by that of the untreated cells.

Establishment of melanoma cell lines carrying an inducible Bim or CHOP expression system. A lentivirus-based inducible gene expression system described previously was used to express Bim and CHOP conditionally in melanoma cells. ${ }^{18}$ Briefly, the system involves coinfection of two lentiviral particles; one encoding the inducible transcriptional activator Gal4 1-147

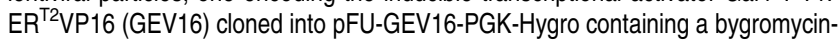
B-resistance gene, and another, Bim or CHOP cDNA cloned into pF-5xUAS-SV40puro containing a puromycin-resistance gene. Dual antibiotic selection was applied deriving a cell population carrying both GEV16 and Bim or CHOP. Application of low $\mathrm{nM}$ concentrations of (4-OHT) drives the expression of Bim or CHOP. The melanoma cell line Mel-RM was used to establish sublines carrying inducible exogenous Bim (Mel-RM.Bim) or CHOP (Mel-RM.CHOP).

Plasmid vectors and transfection. The pCMV6-XL4-Bim ${ }_{E L}(\mathrm{SC} 306048)$, pCMV6-AC-CHOP (SC324377-20), and pCMV6-AC-PP2A-C (SC321401) were purchased from Origene (Rockville, MD, USA). Cells were transfected with $2 \mu \mathrm{g}$ plasmid as well as the empty vector in Opti-MEM medium (Invitrogen, Carlsbad, CA, USA) with Lipofectamine 2000 reagent (Invitrogen) according to the manufacturer's protocol.

Quantitative reverse transcription and real-time PCR. Total RNA was isolated using RNeasy mini kit (Qiagen, Doncaster, VIC, Australia) following the manufacturer's instructions. RNA was reverse transcribed into cDNA using Superscript III (Invitrogen) following the manufacturer's instructions. Quantitative PCR (qPCR) was performed using the ABI Prism 7900 sequence detection system (Applied Biosystems, Mulgrave, VIC, Australia) with specific-gene primers: Bim forward, 5'-TGCAGACATTTTGCTTGTTCAA-3'; Bim reverse, 5'-GAACCGCT GGCTGCATAATAAT-3'; $\beta$-actin forward, $5^{\prime}$-GGCACCCAGCACAATGAAG-3'; $\beta$-actin reverse, $5^{\prime}$-GCCGATCCACACGGAGTACT-3'). The following PCR conditions were used: standard fast cycle $95^{\circ} \mathrm{C}$ for $20 \mathrm{~s}, 40$ cycles of $95^{\circ} \mathrm{C}$ for $1 \mathrm{~s}$ and $60^{\circ} \mathrm{C}$ for $20 \mathrm{~s}$ using Fast SYBR Green mastermix (Applied Biosystems). Cycle threshold $\left(C_{\mathrm{T}}\right)$ values for specific genes were normalized to the $C_{\mathrm{T}}$ value for the house-keeping gene, $\beta$-actin. The fold changes of mRNA expressed were determined by comparison with $\beta$-actin, where the control sample was arbitrarily designated as 1 , and the values of the relative abundance of mRNA of other samples were calculated accordingly. The specificity of the GPCR was controlled using non-template control.

siRNA knockdown. The siRNA constructs used were obtained as the siGENOME SMARTpool reagents (Dharmacon, Lafayette, CO, USA). The siRNA constructs used are: MEK1 siGENOME SMARTpool (M-003571-01-0010), ERK1
siGENOME SMARTpool (M-003592-03-0005), ERK2 siGENOME SMARTpool (M-003555-04-0005), CHOP siGENOME SMARTpool (M-004819-03-0005), and non-targeting siRNA pool (D-001206-13-20) as control. Transfection of siRNA pools was carried out as described previously. ${ }^{40}$

Detection of XBP1 mRNA splicing. Reverse transcription-PCR (RT-PCR) products of XBP1 mRNA were obtained from total RNA extracted using primers $5^{\prime}$-CGGTGCGCGGTGCGTAGTCTGGA-3' (sense) and $5^{\prime}$-TGAGGG GCTGAGAGGTGCTTCCT-3' (antisense). As a 26-bp fragment containing an ApaLI site is spliced on activation of XBP1 mRNA, the RT-PCR products were digested with ApaLI to distinguish the active spliced form from the inactive unspliced form. Subsequent electrophoresis revealed the inactive form as two cleaved fragments and the active form as a noncleaved fragment.

\section{Conflict of Interest}

The authors declare no conflict of interest.

Acknowledgements. This work was supported by the NSW State Cancer Council, Cancer Institute NSW, and National Health and Medical Research Council (NHMRC), Australia, and the Shanxi Scholarship Council and National '863' High Technology Program, China. CCJ is a recipient of postdoctoral training Fellowship of NHMRC. XDZ is supported by a senior research fellowship of NHMRC. We thank Dr. John Silke (La Trobe University, Australia) for the lentivirus-based inducible gene expression system.

1. Harding HP, Calfon M, Urano F, Novoa I, Ron D. Transcriptional and translational control in the mammalian unfolded protein response. Annu Rev Cell Dev Biol 2002; 18: 575-599.

2. Schroder M, Kaufman RJ. The mammalian unfolded protein response. Annu Rev Biochem 2005; 74: 739-789.

3. Boyce M, Yuan J. Cellular response to endoplasmic reticulum stress: a matter of life or death. Cell Death Differ 2006; 13: 363-373.

4. Xu C, Bailly-Maitre B, Reed JC. Endoplasmic reticulum stress: cell life and death decisions. $J$ Clin Invest 2005; 115: 2656-2664.

5. Zhang L, Lopez H, George NM, Liu X, Pang X, Luo X. Selective involvement of BH3-only proteins and differential targets of Noxa in diverse apoptotic pathways. Cell Death Differ 2011; 18: 864-873.

6. Puthalakath H, O'Reilly LA, Gunn P, Lee L, Kelly PN, Huntington ND et al. ER stress triggers apoptosis by activating BH3-only protein Bim. Cell 2007; 129: 1337-1349.

7. Ley R, Ewings KE, Hadfield K, Cook SJ. Regulatory phosphorylation of Bim: sorting out the ERK from the JNK. Cell Death Differ 2005; 12: 1008-1014.

8. Ley R, Ewings KE, Hadfield K, Howes E, Balmanno K, Cook SJ. Extracellular signalregulated kinases $1 / 2$ are serum-stimulated "Bim(EL) kinases" that bind to the BH3-only protein Bim(EL) causing its phosphorylation and turnover. J Biol Chem 2004; 279: 8837-8847.

9. Shi Y. Serine/threonine phosphatases: mechanism through structure. Cell 2009; 139(3): 468-484.

10. Janssens V, Longin S, Goris J. PP2A holoenzyme assembly: in cauda venenum (the sting is in the tail). Trends Biochem Sci 2008; 33: 113-121.

11. Janssens V, Goris J, Van Hoof C. PP2A: the expected tumor suppressor. Curr Opin Genet Dev 2005; 15: 34-41.

12. Roberts KG, Smith AM, McDougall F, Carpenter H, Horan M, Neviani $P$ et al. Essential requirement for PP2A inhibition by the oncogenic receptor C-KIT suggests PP2A reactivation as a strategy to treat C-KIT + cancers. Cancer Res 2010; 70: 5438-5447.

13. Ito $\mathrm{A}$, Koma $\mathrm{Y}$, Watabe $\mathrm{K}$, Nagano $\mathrm{T}$, Endo $\mathrm{Y}$, Nojima $\mathrm{H}$ et al. $\mathrm{A}$ truncated isoform of the protein phosphatase $2 \mathrm{~A}$ B56gamma regulatory subunit may promote genetic instability and cause tumor progression. Am J Pathol 2003; 162: 81-91.

14. Jiang CC, Lucas K, Avery-Kiejda KA, Wade M, deBock CE, Thorne RF et al. Up-regulation of $\mathrm{Mcl}-1$ is critical for survival of human melanoma cells upon endoplasmic reticulum stress. Cancer Res 2008; 68: 6708-6717.

15. Hersey $P$, Zhang $X D$. Adaptation to $E R$ stress as a driver of malignancy and resistance to therapy in human melanoma. Pigment Cell Melanoma Res 2008; 21: 358-367.

16. Jiang CC, Mao ZG, Avery-Kiejda KA, Wade M, Hersey P, Zhang XD. Glucose-regulated protein 78 antagonizes cisplatin and adriamycin in human melanoma cells. Carcinogenesis 2009; 30: 197-204.

17. Zhuang L, Scolyer RA, Lee CS, McCarthy SW, Cooper WA, Zhang XD et al. Expression of glucose-regulated stress protein GRP78 is related to progression of melanoma. Histopathology 2009; 54: 462-470.

18. Vince JE, Wong WW, Khan N, Feltham R, Chau D, Ahmed AU et al. IAP antagonists target clAP1 to induce TNFalpha-dependent apoptosis. Cell 2007; 131: 682-693.

19. Jiang CC, Lai F, Tay KH, Croft A, Rizos H, Becker TM et al. Apoptosis of human melanoma cells induced by inhibition of B-RAFV600E involves preferential splicing of bimS. Cell Death Dis 2010; 1: e69. 
20. Yin $\mathrm{KJ}, \mathrm{Hsu} \mathrm{CY}, \mathrm{Hu} \mathrm{XY}$, Chen $\mathrm{H}$, Chen $\mathrm{SW}, \mathrm{Xu} \mathrm{J}$ et al. Protein phosphatase $2 \mathrm{~A}$ regulates bim expression via the Akt/FKHRL1 signaling pathway in amyloid-beta peptide-induced cerebrovascular endothelial cell death. J Neurosci 2006; 26: 2290-2299.

21. Hsu W, Zeng L, Costantini F. Identification of a domain of Axin that binds to the serine/ threonine protein phosphatase $2 A$ and a self-binding domain. $J$ Biol Chem 1999; 274 3439-3445.

22. Gillespie S, Borrow J, Zhang XD, Hersey P. Bim plays a crucial role in synergistic induction of apoptosis by the histone deacetylase inhibitor SBHA and TRAIL in melanoma cells. Apoptosis 2006; 11: 2251-2265.

23. Wang YF, Jiang CC, Kiejda KA, Gillespie S, Zhang XD, Hersey P. Apoptosis induction in human melanoma cells by inhibition of MEK is caspase-independent and mediated by the Bcl-2 family members PUMA, Bim, and Mcl-1. Clin Cancer Res 2007; 13: 4934-4942.

24. Chen LH, Jiang CC, Watts R, Thorne RF, Kiejda KA, Zhang XD et al. Inhibition of endoplasmic reticulum stress-induced apoptosis of melanoma cells by the ARC protein Cancer Res 2008; 68: 834-842.

25. Jiang CC, Chen LH, Gillespie S, Wang YF, Kiejda KA, Zhang XD et al. Inhibition of MEK sensitizes human melanoma cells to endoplasmic reticulum stress-induced apoptosis. Cancer Res 2007; 67: 9750-9761.

26. Coley AM, Moujalled D, Puthalakath H. The PKA paradox: is Bim the answer? Cell Cycle 2011; 10: 729-730.

27. Zhang L, Insel PA. The pro-apoptotic protein Bim is a convergence point for cAMP/protein kinase A- and glucocorticoid-promoted apoptosis of lymphoid cells. J Biol Chem 2004; 279 20858-20865

28. Woo CW, Kutzler L, Kimball SR, Tabas I. Toll-like receptor activation suppresses ER stress factor CHOP and translation inhibition through activation of elF2B. Nat Cell Biol 2012; 14: 192-200.

29. Christen V, Treves S, Duong FH, Heim MH. Activation of endoplasmic reticulum stress response by hepatitis viruses up-regulates protein phosphatase 2A. Hepatology 2007; 46: 558-565.

30. Deichmann M, Polychronidis $M$, Wacker J, Thome $M$, Näher $H$. The protein phosphatase $2 A$ subunit $B$ gamma gene is identified to be differentially expressed in malignant melanomas by subtractive suppression hybridization. Melanoma Res 2001; 11 $577-585$
31. Mannava S, Omilian AR, Wawrzyniak JA, Fink EE, Zhuang D, Miecznikowski JC et al. PP2A-B56 $\alpha$ controls oncogene-induced senescence in normal and tumor human melanocytic cells. Oncogene 2011; 31: 1484-1492.

32. Hu P, Han Z, Couvillon AD, Exton JH. Critical role of endogenous Akt/IAPs and MEK1/ERK pathways in counteracting endoplasmic reticulum stress-induced cell death. J Biol Chem 2004; 279: 49420-49429.

33. Strack $S$. Overexpression of the protein phosphatase $2 A$ regulatory subunit $B$ gamma promotes neuronal differentiation by activating the MAP kinase (MAPK) cascade. J Biol Chem 2002; 277: 41525-41532.

34. Van Kanegan MJ, Adams DG, Wadzinski BE, Strack S. Distinct protein phosphatase $2 A$ heterotrimers modulate growth factor signaling to extracellular signal-regulated kinases and Akt. J Biol Chem 2005; 280: 36029-36036.

35. Mandic A, Hansson J, Linder S, Shoshan MC. Cisplatin induces endoplasmic reticulum stress and nucleus-independent apoptotic signaling. J Biol Chem 2003; 278: 9100-9106.

36. Rahmani M, Davis EM, Crabtree TR, Habibi JR, Nguyen TK, Dent P et al. The kinase inhibitor sorafenib induces cell death through a process involving induction of endoplasmic reticulum stress. Mol Cell Biol 2007; 27: 5499-5513.

37. Fecher LA, Amaravadi RK, Flaherty KT. The MAPK pathway in melanoma. Curr Opin Oncol. 2008; 20: 183-189.

38. Nikolaou VA, Stratigos AJ, Flaherty KT, Tsao H. Melanoma: new insights and new therapies. J Invest Dermatol 2012; 132: 854-863.

39. Sullivan A, Uff CR, Isacke CM, Thorne RF. PACE-1, a novel protein that interacts with the C-terminal domain of ezrin. Exp Cell Res 2003; 284: 224-238.

40. Yang F, Tay KH, Dong L, Thorne RF, Jiang CC, Yang E et al. Cystatin B inhibition of TRAIL-induced apoptosis is associated with the protection of $F L I P(L)$ from degradation by the E3 ligase itch in human melanoma cells. Cell Death Differ 2010; 17: 1354-1367.

Cell Death and Disease is an open-access journal published by Nature Publishing Group. This work is licensed under the Creative Commons Attribution-NonCommercial-No Derivative Works 3.0 Unported License. To view a copy of this license, visit http://creativecommons.org/licenses/by-nc-nd/3.0/

Supplementary Information accompanies the paper on Cell Death and Disease website (http://www.nature.com/cddis) 